\title{
Implementation of Inclusive Child Friendly Primary Schools Policy in Nyandarua County, Kenya
}

\author{
Daniel Kirogo Wahungu \\ Phd Student, Kenyatta University
}

wahungu.daniel@ku.ac.ke +254723939122

Prof. Ibrahim Oanda: Email: oandaibrahim@gmail.com

Department of Educational Foundations, Kenyatta University

Dr. Violet Wawire Email: wawire.violet@ku.ac.ke

Department of Educational Foundations, Kenyatta University

Accepted February 2020

Published November 2020

\begin{abstract}
The main problem addressed by this study was the implementation of inclusive child friendly primary schools policy in Nyandarua County. The Inclusive Child Friendly Schools (CFS) policy has become the vehicle through which the government is providing quality education for all children in school by creating a learning environment where all children can learn, all children want to learn, and all children feel included in the classrooms and schools. However, studies show that the conditions in schools are not adequately adapted to accommodate the diversity of learners and even many more children of school going age are left out of school. These challenges generated the objectives of the study which were to examine the practice in public primary schools in line with the inclusive CFS policy and suggestion of appropriate strategies for implementation of inclusive CFS in public primary schools. To achieve this, the study utilized a descriptive survey using both qualitative and quantitative methods. Data collection instruments entailed questionnaires, interview schedule, focus group discussions, observation schedule and document analysis which were first piloted to improve validity and reliability and the accruing data was then analyzed thematically as per the study objectives. The findings of the study indicated that there was a substantial gap between CFS policy expectations and its actual day to day practice in the schools. Schools had the CFS messages engraved but had not made a significant alteration in the line with the policy. From these study findings, the paper presented several policy recommendations including adopting CFS policy to internal contexts so that individual schools look for ways of developing and utilizing selfassessment indicators of CFS at the school levels. Though the area of CFS is relatively new, it was hoped the study could shed light on the way forward for inclusive child friendly school programme in Kenya.
\end{abstract}

Key words: Implementation, Inclusive Child Friendly Schools (CFS), Policy, Quality Education, Learning Environment 


\section{Introduction}

The inclusive Child Friendly School (CFS) policy is one of the five components of the CFS. According to the CFS Manual (MoE, 2010:1), the CFS concept has five major components: an inclusive child friendly school; a safe protective school; equity and equality promoting school; health and nutrition promoting school; and enhancing school-community linkages and partnerships. An inclusive CFS implies "transforming of education systems and schools so that they can cater for the diversity of pupils learning needs resulting from their social and cultural background and their individual characteristics as regards learning motivations, abilities, styles and rhythm." (UNICEF, 2013). So in principle, inclusive CFS goes beyond having the learners in school to also endeavour to create a conducive environment for a diversity of learners. According to this perspective, it is not the students enrolled in the school that must adapt to the existing educational provision, but rather the school that should be adapted to the needs of everyone, since all students are different.

According to the CFS manual for Kenyan schools (UNICEF 2010), the CFS programme was initiated by UNICEF in 1999. UNICEF grounded the CFS framework in the 1990 Convention on the Rights of the Child's principles of children's rights, as well as other international human rights instruments and international declarations such as the Declaration of Education for All (1990). In Kenya, CFS was introduced by the Ministry of Education, with the support of UNICEF in 2002 and implemented on a pilot basis in 11 districts: Nairobi, Turkana, West Pokot, Kwale, Isiolo, Marsabit, Moyale, Mandera, Wajir, Garissa and Ijara. In 2010, the Ministry rolled out the programme on a national scale. As such, the CFS is a government policy that all public primary schools were expected to implement.

However, challenges have been alluded to in implementing inclusive CFS. At the global level, a review of policies and interventions provide evidence of the problem of implementation of inclusive CFS. Based on the UNICEF Global Report of 2018, schools struggle to be fully inclusive, particularly in the case of students with disabilities. School buildings and grounds often do not easily accommodate students with physical disabilities, and school heads and teachers overwhelmingly report that they are not equipped to meet the needs of children with special needs (like learning disabilities and developmental disabilities). Furthermore, there are still many children already excluded from school. According to studies carried out by UNICEF (2019), many nations of the world have not achieved Universal Primary Education with an estimate of about 175 million adolescents and youth being left out of school. Among these, about 59 million are in primary school-going age. The reasons impeding the achievement of UPE include poverty, illness, malnutrition, absenteeism and high cost of schooling, cultural factors, inappropriate curriculum, examination, inadequate teachers and lack of facilities.

At the regional level, the problem of exclusion of children of school-going age is still evident and one that calls for attention. Sub-Saharan Africa remains the region with the highest out-of-school rates for all age groups. Of the 59 million out-of-school children of primary school age, 32 million, or more than one-half, live in Sub-Saharan Africa. Southern Asia has the second-highest number of out-of-school children with 13 million. Sub-Saharan Africa also has the highest rate of exclusion, with $19 \%$ of primary-school-age children denied the right to education, followed by Northern 
Africa and Western Asia at 9\% and Southern Asia at 7\% (UNESCO Institute for Statistics Database, 2019). Further, there is the danger that $42 \%$ of African school children will drop out before the end of primary education mainly due to school related factors that have to do with challenges like scarcity of resources, lack of effective school policy and management environment constructive for learning, poor quality and lack of child-centered teaching and learning processes and outcomes.

From the above information, it can be deduced that even at the global and regional levels, schools had not found appropriate ways of transforming the school environments to accommodate the diverse needs of their learners and the practice in line with the inclusive CFS policy. This concern at the global level laid the foundation for the objectives of this study.

Implementation of inclusive environments in Kenya has had even greater challenges in the era of FPE. The Task Force on the Re-alignment of the Education Sector to the Constitution of Kenya 2010 notes that: "One of the effects of the introduction of FPE in 2003 was an upsurge in pupil enrolments, from 6,131,000 to 7,117,300, an increase of nearly one million. The upsurge was at its peak in Standard One, which registered an increase of over 330,000 pupils. The negative effect of that was the drop in the quality of education due to understaffing, inadequacy of learning materials and crowded classrooms (MoE, 2012:61).

There are already concerns that the implementation of inclusive CFS in Nyandarua County, the area under study, has been confronted by challenges. According to the Education Management Information System (EMIS) Unit MoE (2013), "Upon the introduction of FPE in 2003, there was a very high enrolment that was probably among the best in the country. Consequently, schools began to experience the pressure of large enrolments made worse by inadequate educational support within the schools; lack of individual support for learners; difficulty in identifying the personal and specific needs of individuals and pressure on available resources. Further, it led to overstretched facilities, overcrowding in schools, inadequate teaching and learning resources and high pupil-teacher ratio." These are push out factors within the school, therefore, barriers impeding the implementation of inclusive CFS. The EMIS noted that in the years that followed, primary education was characterized by declining enrolments, transitional, and survival rates against rising drop out and repetition rates.

Moreover, a study carried out in the area under study, (Kanjogu: 2013) shows that due to the enrolment gains through the FPE program, there were the challenges of high pupil-teacher ratio, high pupil-textbook ratio, crowded classrooms and strained teaching- learning resources as well as facilities like toilets, water and playing grounds. There are thus impediments on individual learner participation, which is critical to attainment of inclusive CFS, leading to high repetition rates, declining enrolment and low completion rates in Nyandarua County.

In spite of the above mentioned challenges in the implementation of inclusive CFS, there is no evidence that a systematic research study has so far been conducted in Nyandarua County on the same. This gap created the need for this study. 


\section{Objectives}

The study aimed at achieving the following objectives:

i. To examine the practices in public primary schools in Nyandarua County in line with the inclusive CFS policy.

ii. To suggest appropriate strategies for the implementation of inclusive CFS in public primary schools in Nyandarua County.

\section{Methods}

This study made use of descriptive design utilizing both qualitative and quantitative approaches. According to Orodho, the descriptive design is used in preliminary and exploratory studies to allow researchers to gather information, summarize, present and interpret for the purpose of clarification (Orodho: 2002). Similarly, Mugenda and Mugenda (2003) point out that descriptive survey research is intended to produce statistical information about aspects of education.

The independent variable was the implementation of inclusive CFS as defined by the way schools' management and leadership in Nyandarua County had adapted appropriate systems of incorporating all pupils, whether the schools had enhanced their capacities towards the provision of inclusive CFS and whether they had transformed the curriculum and teaching process commensurate with the inclusive CFS standards. "The independent variables are also known as the predictor or explanatory variables. These are the factors that the researcher thinks explain variation in the dependent variable" (Kombo and Tromp 2006:21). The dependent variable was the inclusive child friendly school programme since this was the expected outcome of the research.

There are 49 public primary schools in Nyandarua South Sub-County which were the target population. The population of the pupils is 10238 boys, 9659 girls which makes a total of 19897 pupils. The number of teachers was 493. Nyandarua South Sub-County has three zones; Engineer, Ndunyu Njeru and Murungaru Zones each under a Zonal Quality Assurance and Standards Officer (ZQASO).

Considering the nature of the sample study and geographical spread of the key informants, the researcher used different instruments: Questionnaires, interviews, Focus Group Discussion (FSD), Observation schedule and content analysis. This is enunciated by Mugenda and Mugenda (1999) who argue that in social science research, the most commonly used instruments are questionnaires, interview schedules and observational forms.

There was both qualitative and quantitative data. Qualitative data was written down and narrated by the researcher. The analysis of this data considered the inferences that were made from the opinions of respondents. The analysis was then be presented thematically in a narrative form and where possible in tabular form. Quantitative data was analyzed using descriptive statistics and recorded on the tally table from which frequencies for all question items were prepared and then percentages computed manually. According to Gay (1992), descriptive statistics permit the researcher to meaningfully describe many scores with a small number of indices. 
Simple descriptive statistics were used and the data thereof presented in form of tables, charts and graphs: Graphic representation of data is a valuable supplement to statistical analysis. The graph enables the reader to see the trend of the distribution more easily than is possible by simply looking at numbers in a frequency distribution (Mugenda and Mugenda, 1999:126). The data was analyzed according to objectives. From the analysis of data, the researcher was able to interpret the findings and draw conclusions. This in turn enabled the researcher to come up with suggestions and recommendations depending on the interpretations that come out as a result of the study.

\section{Results and discussion}

In the study, one ZQASO, 15 head teachers and 50 teachers had been targeted. The return rate for both head teachers and teachers was $94 \%$ and hence deemed adequate for data analysis. Five focused Group discussions of 6 pupils each: 3 boys and 3 girls participated in the focused group discussion as scheduled. The return rate was computed to confirm if the study meets the threshold for proper data analysis and interpretation.

The study looked at ways in which schools were implementing inclusive CFS by looking at the learning environment for children in primary schools. In trying to unpack this broad area, the study relied on the CFS Monitoring Toolkit to identify nine key areas. The following nine areas were accordingly identified as critical to understanding school practice of inclusive CFS in the area under study: teaching-learning environment, teacher-pupil ratio, pupil-textbook ratio, repetition of classes, gender responsiveness, water and sanitation, playing grounds, corporal punishment and catering for the diversity of learners.

This is underlined by UNICEF (2012) in asserting that the schools' physical condition is the most important and fundamental aspect of a child-friendly environment. School's physical infrastructure encompasses school land and compound, school building, classrooms, laboratories, library, furniture, toilet, drinking water, playground, educational aids, black/whiteboards, audio-video materials, cupboards, electric equipment, computers, canteen, hostel and protection room, etc. The physical aspect of school crosscuts other aspects of a child-friendly educational environment. Therefore, special attention should be paid to the management of the physical aspects among other diverse aspects of child friendly school. In the same manner, since sound physical condition plays an important role in imparting quality education, it is necessary to pay particular attention to this aspect.

\section{Teaching/learning environment}

The expectations for an inclusive CFS teaching-learning environment are articulated in the CFS toolkit that states that "The goal of an inclusive, learning-friendly classroom is active students. Students who actively and enjoyably participate in classroom learning have fewer disciplinary problems. They want to be there, and they will do whatever is necessary to stay there" (UNESCO: 2004).

To begin, with teachers complained of heavy workloads and to countercheck this, the researcher sought to find out the teaching load of teachers per week. Teachers teaching loads in 15 of the 
sampled schools were taken and computed to give a picture of what was happening on the ground. From the findings, the majority of the teachers (53\%) said that they had over 30 lessons per week, $31 \%$ of the teachers had 24-29 lessons while 16\% had 15-23 lessons per week. This clustering was generated from MOE guidelines with the help of teachers, head teachers and the ZQASO on what is generally considered as high, average and low. The low workloads are usually set for those in administration.

The current staffing norm in schools in Kenya was brought about by a major policy reform implemented in 1984 leading to the use of Curriculum Based Establishment (CBE) which specified a minimum teaching load of 27 lessons per week (MOEST, 2005b; TSC, 2007). Furthermore, relying strictly on the CBE may lead to a compromised situation for the diversity of learners who need individual and sometimes special attention.

These responses were first tabulated then computed and presented in Figure 4.1 below for a more vivid view of the situation.

Figure 4.1 Average teachers' workload per week in 5 sampled schools term 12016

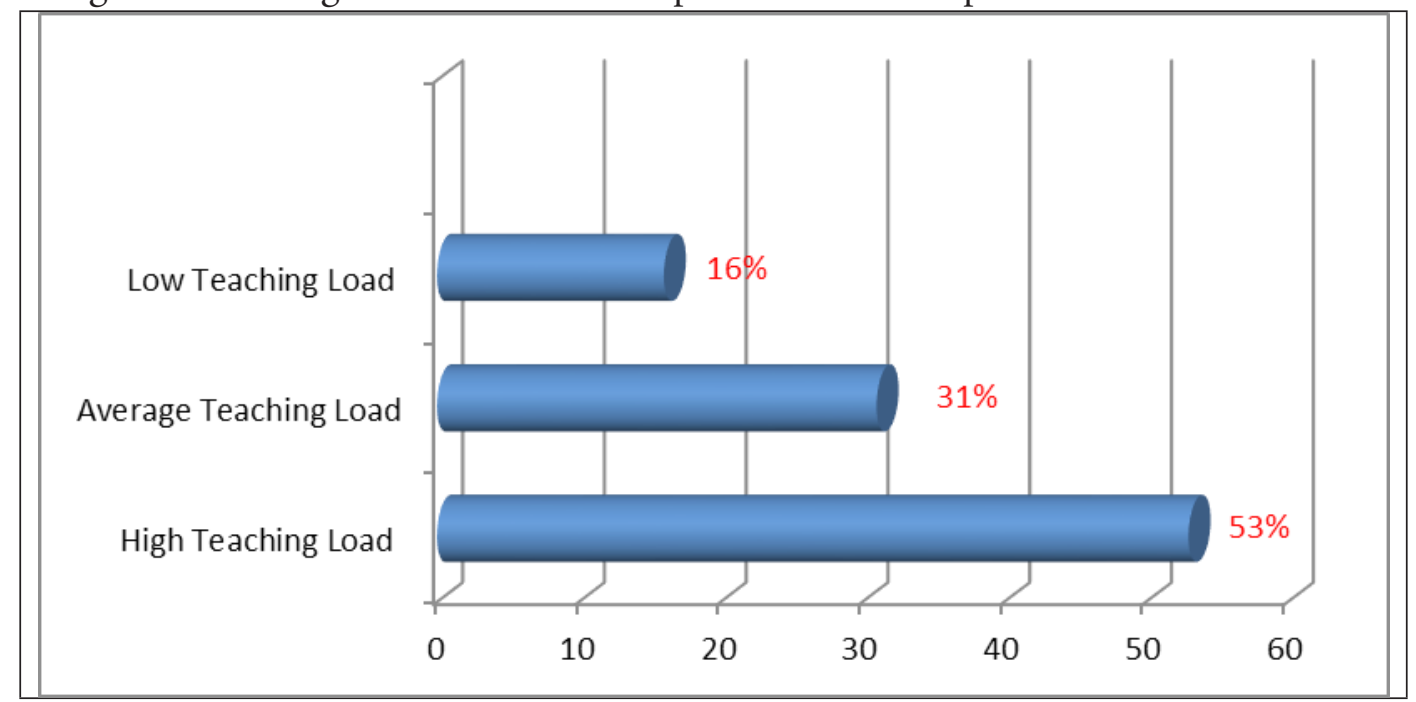

The findings and analysis in figure 4.1 above indicate that the teaching loads for the teachers are too high which compromises the quality of education they offer to the pupils as they do not have adequate time to prepare for lessons. When this is coupled with high teacher-pupil ratio, discussed elsewhere in this study, teaching-learning environments are compromised.

This teacher focused pedagogy can be juxtaposed with the CFS situation in India. The idea of childfriendly practices has gained increasing currency in Indian education policy in recent years. The National Curriculum Framework (2005) strongly recommends the use of child-friendly pedagogical practices such as increasing pupil participation during classroom sessions, shifting away from rigid classroom teaching structures, creating more lively classrooms and drawing on pupils' experiences to enrich lessons and provide examples. In addition, participation teaches children skills such as knowing how to contribute ideas, listen to others, and synthesize new information. These skills are valuable for inclusive CFS. Crowded classrooms have implications for inclusion and quality of 
education since the diversity of learners are not given the due individual attention that they need.

\section{Teacher- pupil ratio in line with inclusive CFS}

The pupil-teacher ratio is one measure of assessing progress towards inclusive CFS. The primary school pupil-teacher ratio is the number of pupils enrolled in primary school divided by the number of primary school teachers (regardless of their teaching assignment). The average teacher/learner ratio in this county is $47: 1$, which means that there is one teacher for every 47 learners in the school. This is above the recommended teacher-pupil ratio of 1:45 that Kenya is aiming to achieve and thus reflecting a challenge of limited staff and a large number of pupils.

These statistics indicated a high pupil-teacher ratio in the lower classes. The implication of this is that it affects the learning of basic skills in reading, writing and arithmetic. In the lower classes, the pupils need more personalized attention to acquire the skill well. According to the Kenyan Uwezo report 2013, a high pupil-teacher ratio affects the quality of education offered. The size of a primary school, as measured by the number of formally enrolled pupils, provides a first indication of pressure on school resources, and in particular the potential for teachers to get to know and provide due attention to individual pupils. We find that many children who attend school are not learning basic skills within the first few years of education. Thus, the inclusive CFS education cannot be effectively delivered.

Consequently, a high pupil-teacher ratio in this county is identified as a challenge to the implementation of inclusive CFS. The high pupil-teacher ratio denies the pupil individual attention from the teacher and slows down learning. Moreover, studies have indicated that teachers are the most important of the school-related factors affecting student achievement through their effectiveness (Orodho, 2013).

\section{Pupil - textbook ratio commensurate with inclusive CFS}

The study carried out observation of standard 6 class English lessons to get the pupil-text book ratio. English is a key subject for the acquisition of reading skills and has a spiral effect in understanding other subjects. The researcher took into consideration the approved list of textbooks and other instructional materials, Revised $13^{\text {th }}$ Edition of January 2014 (MoE, 2014). In the content analysis and classroom observations, the study sought to find out how many pupils were sharing a textbook, whether these materials were in good condition and child friendly.

The classroom observation data may only be used as a third source of information on the state of textbook availability since textbooks per pupil ratios were collected only for those textbooks being used physically in the classroom. It may not paint a complete picture since some books may be borrowed and others left at home. However, it helps to demonstrate the state of textbooks in schools. 
Table 4.1 Ratio of sharing English textbooks among class six learners in sample School G in term one 2016

\begin{tabular}{|l|l|l|l|}
\hline Rate of sharing & $\mathbf{N}=\mathbf{4 7}$ & $\mathbf{\%}$ & MoE guidelines on textbook ratio ( 2014) \\
\hline 1 Each & 2 & 4 & Excellent \\
\hline 1 between 2 pupils & 8 & 17 & Satisfactory \\
\hline 1 between 3 & 23 & 49 & Unsatisfactory \\
\hline 1 between more than 3 & 14 & 30 & Poor \\
\hline
\end{tabular}

The above data show that $79 \%$ of pupils in the county have an unsatisfactory textbook ratio as per the MoE guidelines on textbook ratio. The MoE recommends at least a ratio of 1 between 2 (MoE: 2014). This is further complicated by sitting positions in crowded classes and visibility in classrooms with poor ventilation.

Earlier studies by Glewwe (2009) seem to show similar trends in Kenya. In a study conducted in Kenya, a sample of 80 percent to 90 percent of the textbooks pupils had been bought by their parents. Even after including textbooks purchased by parents for pupils in class 3, 4, and 5, only one out of six pupils had English and Math textbooks. In class 6 and 7, one in four had these textbooks. Very few had textbooks in other subjects. Pupils in class 8 had more textbooks. About 40 percent of class 8 pupils had Math and English textbooks.

Access to textbooks even if they are shared is important for effective learning and for all pupils to feel included in the learning process. There are implications for marginalized pupils in case they have reading problems in an environment of limited books. This challenge of lack of basic learning materials for pupils is further collaborated in other studies. According to African school systems (2011), only 78 percent of the Standard 6 pupils had at least one exercise book, a pencil or a pen, and a ruler. In other words, only one in every five (22\%) pupils did not have all the three basic learning items that were considered necessary for effective participation in classroom activities. This was part of a major international study known as the Southern and Eastern Africa Consortium for Monitoring Educational Quality (SACMEQ) III Project. The SACMEQ III Project sought to examine the quality of education provided in primary schools in Kenya and 14 other African school systems.

\section{The practice of making pupils repeat classes}

Repetition of classes has been identified as one of the push-out factors in primary school education and hence an impediment to the implementation of inclusive CFS. From the content analysis of a sample in class 6 in sample school J, a high repetition rate was noted. The repetition rate is derived by analyzing data on enrolment and repeaters by class for three consecutive years. Repetition rate ideally should approach $0 \%$; a high repetition rate reveals problems in the internal efficiency of the school which ideally is a push out factor for pupils. For example, as seen in table 4.6, $18 \%$ of the learners had repeated class 3 and more boys had repeated than girls. 
Table 4.2 - Repetition rates for class 6 (2012-2014) in sampled school F

\begin{tabular}{|l|l|l|l|}
\hline Class & Boys & Girls & Repetition Rate (\%) \\
\hline Class 3 & 11 & 13 & 18 \\
\hline Class 4 & 5 & 8 & 11 \\
\hline Class 5 & 6 & 3 & 6 \\
\hline
\end{tabular}

According to ZQASO, learners with special needs like those slow to learn are forced to repeat classes and may end up dropping out. The ZQASO as well as head teachers acknowledge that girls are affected more by the repetition of classes in class six, seven and eight due to a multiplicity of factors like family responsibilities and the lure of teenage sex.

A growing body of research from UNESCO shows that girls and other disadvantaged groups have a higher chance of repeating classes and drop out. According to UNESCO (2012), disadvantaged groups such as girls, children living in poor communities, children on wage labor and orphaned children as most vulnerable to poor attendance, repetition, early dropout and exclusion. In the classroom: Large numbers of over-age students present a challenge for teachers who must teach a more diverse group with differing levels of maturity and school preparedness. Both late entry into primary school and grade repetition can cause children to be over-age for their grade.

Learners going through constant repetition will eventually drop out of school. Their self-esteem is affected since they find themselves in class with their juniors in age. This is confirmed in earlier studies. In developing countries, each year 6.2 percent of primary students repeat a grade, compared to 0.8 percent in developed countries; and 25.5 percent drop out of primary school, compared to 2.3 percent in developed countries (UNESCO 2016).

\section{Gender responsiveness teaching and learning environments}

In evaluating the gender responsiveness of the classroom, the researcher could not exhaustively look at as many indicators since the study is not entirely on gender. Some of the following were looked into in this regard: the level of participation of boys and girls in classroom activities; sitting arrangements for both boys and girls; how the classroom environment supports learning for both boys and girls; physical aspects like cleanliness, adequate and relevant infrastructure like furniture, conditions of the floor, walls, ventilation, etc.; learning aids present in the classroom and whether they are gender-sensitive; and whether the teacher concentrates mainly on any gender. The conditions of the class would affect both boys and girls differently.

One observation session of teacher-pupil interactions in the classroom situation was made in each of the 5 of the sampled schools. For each activity, the researcher considered only the specific number of pupils who took part in it. Therefore the variance in the value of $\mathrm{N}$ is per participants in that activity for the period under observation. A summary of the frequencies of interactions is made in table 4.3 below: 
Table 4.3 A summary of frequencies of interactions in class for a Mathematics class in standard 6 in sampled school C term one, 2016

\begin{tabular}{|l|l|l|l|l|}
\hline \multirow{2}{*}{$\begin{array}{l}\text { Interaction between the teacher and the } \\
\text { learner }\end{array}$} & \multicolumn{4}{|c|}{ Frequency } \\
\cline { 2 - 5 } & Girls & $\%$ & Boys & $\%$ \\
\hline Learner dominates the class & $3 / 8$ & 37.7 & $5 / 8$ & 62.3 \\
\hline Teachers marking pupils work & $6 / 14$ & 42.9 & $8 / 14$ & 57.1 \\
\hline Learners asking questions to the teacher & $3 / 7$ & 42.9 & $4 / 7$ & 57.1 \\
\hline Learners responding to the teacher's & $9 / 16$ & 56.25 & $7 / 16$ & 43.75 \\
\hline Learners writing on the chalkboard & $0 / 3$ & 0 & $3 / 3$ & 100 \\
\hline Average percentage participation & & 44.94 & & 55.06 \\
\hline
\end{tabular}

From the above observations, teachers went out their way to involve boys more than girls as evident in the marking of books. Secondly, boys tended to dominate classes more than the girls and asked more questions. The girls may have demonstrated higher response to teachers' questions but there was a big discrepancy in the use of the chalkboard. Female pupils $\mathrm{N}=0 / 3$ during the period under observation were hesitant to participate by writing on the chalkboard.

These findings are consistent with research findings that show the environment that tends to favour boys as opposed to girls. "Observations of classroom practices show that teaching and learning is largely gender biased. Many teachers apply teaching methodologies that do not give girls and boys equal opportunities to participate. They also use teaching and learning materials that perpetuate gender stereotypes. Consequently, there is an urgent need to introduce gender responsive pedagogy (FAWE: 2005). This is a sign that schools in Nyandarua County have not provided gender responsive teaching and learning environments as recommended by inclusive CFS.

These findings are given impetus by a study on the effects of FPE. "The effect of FPE on teacher's teaching/learning methodology is profound due to increased pupil-teacher ratio in both primary and secondary schools due to over-enrolment and the resultant overcrowding in classes. This has in effect impacted negatively on teaching as teachers are unable to create effective teacher/ student interaction and is more pronounced for marginalized groups of children who require more personalized consideration. As a result, teachers are increasingly unable to give personal attention. The Government of Kenya acknowledges that although the pupil-teacher ratio at the national level may show that the country has achieved the recommended ratio of 45:1, there are still regional disparities," (Republic of Kenya/UNESCO, 2012).

\section{Water and sanitation that is favourable for inclusive CFS}

The child-friendly approach to school hygiene, sanitation and water seeks to design, put up and uphold learning environment facilities that are hygienic and safe to use and can be sustained and maintained by the school community itself.

The schools in Nyandarua County are well served with safe drinking water that is adequate for the needs of the learners. This is reflected in the 2014 Basic Education Statistics booklet facilities that show a very high access to water with 92 percent primary schools in the county having water. 
However, school observation shows that the watering points were not user friendly since they are soggy and not well-drained. Additionally, it was observed that although all schools have separate, gender specific latrines, the majority of the toilets are not in good condition in terms of spacious cubicles, appropriate aperture and privacy.

On the issue of sanitation and hygiene, toilet ratios had an average of approximately 1: 67 for boys and 1: 48 for girls for sampled schools. This is a reflection of crowding and way below standard. The World Health Organization recommends a student-toilet ratio of 1:30 for boys and 1:25 toilets for girls. These ratios are therefore high and worrying thus portraying an environment that is not conducive for inclusive CFS.

Arguing more specifically that the lack of access to separate and decent toilets is impeding girls' access to their education, UNICEF and the International Water and Sanitation Centre have commented that "Education for girls can be supported and fostered by something as basic as a girls-only toilet" (UNICEF 2015). Consequently, a growing number of organizations are calling

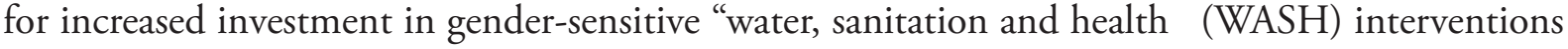
in schools, through such initiatives as Raising Clean Hands for WASH in Schools (Raising Clean Hands 2010).

The researcher established that both boys and girls are sensitive to sharing toilets with younger learners as they progress in age and size. The FGDs indicated that some boys in class seven and eight may have undergone initiation as per the culture of the catchment area. This would thus call for a separation in the use of facilities with the young ones. This can hence be a push out factor for them.

The CFS policy calls for facilities that are sensitive to the needs of the kind of learners who come to school to enhance inclusion. According to WHO (2014), poor environmental conditions in the classroom can also make both teaching and learning very difficult. Girls and boys are likely to be affected in different ways by inadequate water, sanitation and hygiene conditions in schools, and this may contribute to unequal learning opportunities. Sometimes, girls are more affected than boys because of the lack of sanitary facilities means that they cannot attend school during menstruation. The international policy environment increasingly reflects these issues. Providing adequate levels of water supply, sanitation and hygiene in schools is of direct relevance to the United Nations (UN) Millennium Development Goals of achieving universal primary education, promoting gender equality and reducing child mortality. It is also supportive of other goals, especially those on major diseases and infant mortality.

\section{Playing time and playing grounds in line with inclusive CFS}

According to UNICEF (2007), sports and expressive arts must be provided for in the timetable in schools as physical education because sporting activities are necessary for child friendly spaces. In fact, playing is one of the important components of inclusive CFS since it is here that children feel free and mingle freely. It provides for physical, emotional as well as intellectual growth of the child.

The Ministry of Education allocates three PE lessons per week for the upper primary level. However, the results of the study revealed that although PE lessons are allocated in the timetable as per policy, these lessons are converted into classwork. This problem is twofold: inadequacy of facilities and the exchange of PE into classwork. 
In fact, the children in the FGDs expressed the desire for more time in the field since they rarely got the same at home. Most of the days are spent in school and they arrive home late and cannot play. The effects are more prominent for marginalized groups since it leads to more isolation and inactivity especially for those who could be physically handicapped. Observation in five of the sampled schools revealed that schools have a couple of balls put at a corner in the staffroom. Children out for PE were playing with a ball and girls were spectators and chatting away.

According to the KIE ECDE Syllabus (2008), failure to provide child-centered outdoor environments for children during their formative years can inhibit the acquisition of physical (motor) and perceptual skills. A playground that provides adequately for the needs of children, including those with special needs, also provides opportunities for children to satisfy their inquisitive nature and innate desire to discover and be creative.

The physical size of the playing grounds was also becoming a challenge. The ZQASO substantiated this by noting that there was a trend for each primary school to have a day secondary school in the county and this was eating up part of playing grounds. Although this was not a government policy, per se, the trend was widely accepted and space was becoming an issue where hitherto space was adequate.

The end result was less time for children's play time and schools are less children friendly. The importance of playing activity for inclusive CFS cannot be gainsaid. "The benefits of school playtime are widely acknowledged, yet many schools have reduced the time available for playtime. This has been due to a combination of factors, including more pressure on curriculum time, the perceived deterioration of the behaviour of children at playtime and concerns about health and safety. However, there have been many calls for playtimes to be valued as an important part of the school day and children themselves have reported that school is the main chance they have to spend time playing with their friends" (WHO: 2007).

\section{The practice of Corporal punishment in an inclusive CFS environment}

The CFS model (2014) calls for, among others, a policy that is open towards enrolment and encourages retention and one that prohibits corporal punishment instead encouraging the use of child friendly disciplinary efforts that promote cooperative and active learning, tolerance, caring, creativity and above all, promotes the self-esteem and wellbeing of children. Corporal punishment is also in contravention of the Kenya law. The Kenyan government banned corporal punishment in Kenyan schools in 2001 and enacted the Children's Act (Government of Kenya, 2001) which entitles children to protection from all forms of abuse and violence.

However, the study established that schools continue to administer corporal punishment in form of caning, pinching or hair pulling; forcing a child to stay in uncomfortable positions like kneeling or squatting, forcing a child to undergo too much physical exercise or laborious activity like cutting glass and verbal abuse.

In the questionnaire, teachers had been asked if there is corporal punishment in their schools and 
all of them $\mathrm{N}=47$ indicated yes. The explanations the teachers gave showed that they believed that it was difficult to instill proper discipline without some form of corporal punishment since most of the pupils responded more promptly to it than any other form of deterrent.

Observation around schools found pupils undergoing various forms of punishment like kneeling, cutting glass, carrying objects around and running around the field many times. Teachers indicated that corporal punishment, though banned by the government was still a common form of retribution in schools.

Studies have confirmed the negative effects of corporal punishment in making schools unfriendly to the child. "Although corporal punishment is used in schools with the purpose of controlling the students' behaviour and discipline, research has proven that it produces an adverse effect of what it is meant to achieve particularly student's deferral from school and failure, school dropouts, and damage to school assets. Moreover, both dismissing students from class and physically punishing them highly raises the percentage of students escaping from school before the school day finishes" (Wasef, 2011).

It is also a concern by CFS policy which indicates that corporal punishment causes both physical and emotional pain in the learner. While corporal punishment is meant to cause physical pain, emotional punishment is meant to humiliate the child and cause psychological pain. Similar to negative verbal punishment, but much more severe, it can include public ridicule, sarcasm, threats, name-calling, yelling, and commanding, or other humiliating actions, such as denying a child clothing or food or forcing them to stay in undignified positions for everyone to see and comment on. (Clair, 2011).)

\section{Catering for the diversity of Learners in teaching methodology}

To accommodate all pupils with different abilities and across different segmentations in line with inclusive CFS, teachers may need to modify the classroom environment, adjust their teaching strategies, or make other adjustments. Teachers were asked whether they had made any specific provisions for various pupils in their teaching methodology. The following was a recording of their responses.

The above data was combined and presented in the form of a pie chart (figure 4.2) for a clearer exhibition and appears as presented below:

Figure 4.2 Responses of teachers on specific provisions made for the diversity of learners in their class

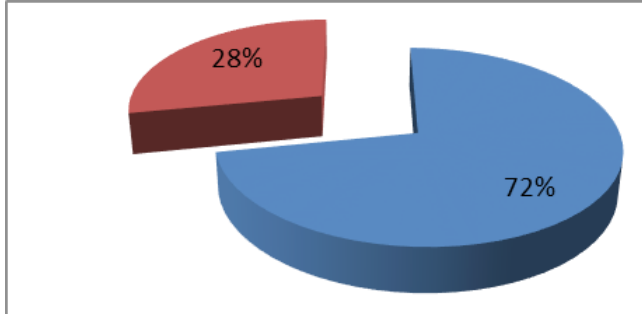

No provisions made for diversity of learners

- Specific provisions made for diversity of learners 
The illustration above shows clearly that only an approximate dismal $28 \%$ of the teachers had appropriately modified their classes and instructional approach to address the diverse needs of their learners. Examples of some of the expected accommodations include: preferential seating, extended time on tests and assignments, reduced homework or class work, verbal, visual, or technology aids, behavior management support occupational or physical therapy, adjusted class schedules or grading, verbal testing, excused lateness, absence, or missed class work, pre-approved medical visits and accompaniment to visits. The key to the success of inclusive CFS in the classroom is based upon the ability to make appropriate adaptations, accommodations, and modifications made to the instruction and other classroom activities.

In fact the sampled schools $\mathrm{N}=14$ did not have data on the different kinds of learners other than sex disintegrated data. The CFS policy expects schools to keep records of the diversity of children so that they can be given special attention as the need may arise. Schools should be in possession of the necessary inventory by quantity corresponding to the levels and needs of education for all pupils. (MoE, 2010:8)

Previous studies have identified schools' unpreparedness to embrace the diversity among learners. A study carried out in Embakasi district Nairobi, Kenya by (Maina, 2012) shows that almost all primary schools are far from being ready to serve the needs of diversity of children. Classrooms, latrines and desks, as well as the behaviours of teachers, peers and the community at large, do not seem welcoming for children with special needs. The evident practice in public primary schools in line with inclusive CFS policy demonstrated in the discussion above helps to lay a foundation for the understanding of limitations below.

\section{Strategies to Improve the Level and Quality of Inclusive CFS Programme}

Respondents were asked to suggest ways of improving the level and quality of inclusive CFS programme. It was clear from the responses that they appreciate that the inclusive CFS would play a chief role in ensuring that all learners are fully included in the education system and that schools' internal environments are made favourable for them all. The following were the main recommendations from the respondents: adopting CFS policy to internal contexts, enhanced provision of facilities for CFS and adoption of appropriate teaching methodology, training of teachers on CFS policy and increased funding for CFS.

\section{Adopting CFS policy to internal contexts}

The study found out that there was a need for schools to adopt the CFS policy to their individual contexts and to have self-assessment of CFS indicators at the school levels. Respondents pointed out that each school is unique in its own way and for this reason, there is a need for schools to look into ways of customizing the policy to make it easier for implementation. Even head teachers agreed that each school has opportunities that can be utilized to improve the school and make it more inclusive.

Studies by UNICEF show that schools should realize that the potential of all stakeholders, including children, for making their respective schools more inclusive and friendly. For example, in 2014, 
UNICEF Kenyan Country Office (Education and Young People) teamed up with the Eastern and South African Regional Office Innovation Team to co-create and co-facilitate a groundbreaking, innovative child-centered design workshop in Nairobi, Kenya for 25 county-wide elected children's government officials to gain their insight on "What can children do to make their schools childfriendly?”

In fact, the researcher observed a lot potential in the sampled schools in terms of human resource, time, space and material resources that could be improvised and harnessed for the success of inclusive CFS.

\section{Facilities and Teaching Methodology}

An analysis of episodes from classroom observations conducted in the primary school revealed the need for facilities and resources to enhance inclusive CFS. Further, it was noted that there is a need to improve teaching methodology commensurate with inclusive CFS.

As noted in the discussions above, some basic facilities like: classrooms, furniture, staffroom, office, stationery, textbooks, teaching aids, library, toilets, clean water, playing field, games equipment, and special education equipment are critical for effective teaching and learning.

These are resources needed to enhance the implementation of inclusive CFS. It is therefore incumbent upon the $\mathrm{MoE}$ to look into the issue of providing facilities. It was also noted that pupils were not provided with opportunities for active participation in class which is a basic standard in inclusive CFS. "The classroom process should not be one in which children are passive recipients of knowledge dispensed by a sole authority, the teacher. Rather it should be an interactive process in which children are active participants in observing, exploring, listening, reasoning, questioning and 'coming to know" (MoE, 2014; 13).

\section{Training of Teachers on CFS}

As noted earlier, $93 \%$ of the sampled teachers had not attended any training or orientation on the CFS policy yet they are expected to be part of the implementation. All the teacher respondents called for training on the CFS policy so that they can understand it well and thus implement it well. The ZQASO was of the view that, the government through KEMI should train all teachers in the policy so as to enhance awareness and thereby effective implementation.

Thus, the findings of the study were that at the national level, the MoE in partnership with international agencies like UNICEF is expected to ensure successful mainstreaming of the CFS policy across all public primary schools by providing in-service training for teachers. The ministry should also infuse the same in teacher training programmes. At the school level, the responses from the teachers were that the head teacher should organize for the dissemination of CFS information to all stakeholders for concerted efforts across the board.

Currently, KEMI is providing training to all head teachers, deputies and selected senior teachers on CFS. It is hoped that this training will be cascaded to all teachers. This is the only way teachers can embrace and further employ their professional competency and innovation to take the inclusive 
CFS to another level. The Global Monitoring Report: Education for All, 2000-2015, pointed out that teachers needed to go for in-service training in order to strengthen their skills and competency.

\section{Funding for CFS}

The head teacher, teachers and the ZQASO, opined that the issue of funding of CFS should be addressed as there has been no funding for the same so far.

Secondly, delays in the disbursement of FPE funds do affect all other sectors of primary school education. FPE was introduced in 2003 for all public primary schools in Kenya. However, it has been hit by constant delays in reaching the schools in due time. This adversely affects the provision of services and education in the school as this is the only funding coming to the school. All the respondent teachers called for the hiring of more teachers to ease the burden of workloads and high pupil-teacher ratios. This is the responsibility of the MoE.

Furthermore, it was evident that there is a challenge around the monitoring of CFS standards in schools. The study established that MoE still relies on traditional paper based analysis which is costly and time consuming, resulting in the incomplete or non-existent analysis. The MoE ought to introduce more technological effective tools that will give feedback more rapidly and effectively.

\section{Summary and Conclusions}

Specifically, the study noted that teaching learning environments that are not conducive for inclusive CFS, high pupil-teacher ratios that compromise the pedagogy and lack of sufficient textbooks to aid learning. The study noted high repetition rates in schools that demotivated learners and led to drop out. Although the study noted a relatively balanced gender responsive environment, the girls are disadvantaged in several ways and not provided with an adequate inclusive environment in view of their individual needs. Facilities like water and sanitation are almost sufficient but their conditions are not tailored for inclusion. The issue of corporal punishment which has both physical and psychological negative effects on pupils was noted to be prevalent in our schools. It is one of the push out factors in CFS. Generally, the study noted that schools were not well prepared to receive a diversity of learners which is the main tenet of inclusive CFS. In essence, all these are push out factors that precipitate low morale of learners, absenteeism, low attainment and eventual drop out of school.

To deal with the limitations and challenges cited, the main recommendations of the study include adopting CFS policy to internal contexts in order for each school to take advantage of whatever resources are at its disposal to create a child friendly school. Secondly, the enhanced provision of facilities for CFS by the government is critical since many schools lack basic facilities that are obligatory in creating a child friendly school. This is a prerogative of the government. Thirdly, it is evident that there is a need for adoption of appropriate teaching methodology which is closely tied to the training of teachers on CFS policy and increased funding for CFS. Teachers need training on CFS policy in order for them to grasp the demands of a diverse class thus the need for a versatile teaching approach that brings all learners on board. 
The issue of funding for CFS needs to be clearly defined so that there does not seem to be a vacuum between partners and MOE. Initially, the programme started with funding from UNICEF but from the findings of the study, it is not clear who is presently funding the programme.

To address the problem of grade repetition and dropouts among disadvantaged groups, policy measures need to address the reasons behind poor attendance, the quality and relevance of the curriculum and provide sufficient support for teachers. It is also important to address individual pupils' needs, particularly those who are slow learners and at risk of repeating and consequently dropping out before completing primary education.

The Government ought to increase funds allocated to FPE so as to enable schools to acquire more facilities. Additionally, the government ought to look into the issue of delayed disbursement of funds for it reflects and constrains the provision of resources for the smooth running of CFS. The findings of this study revealed the fact that there has not been feedback on the inclusive policy as is being practiced in Kenya. The Ministry should also ensure there is monitoring and evaluation of CFS. This would provide the necessary feedback to help improve the programme.

\section{References}

Clair, N. (2011). Elements of Child-Friendly Schools in Macedonia. In Unpublished notes from UNICEF CIS/CEE Regional Meeting, Skopje, Macedonia]. Miske Witt \& Associates.

Glewwe, P., Kremer, M., \& Moulin, S. (2009). Many children left behind? Textbooks and test scores in Kenya. American Economic Journal: Applied Economics, 1(1), 112-35.

Kenya Institute of Education. (2008). Teacher Certificate in Early Childhood Development and Education Syllabus. Nairobi: KIE

Kiumi, J. K., Wanyoike, S. N., \& Kibe, S. M. (2013). The Influence of School-type and School

Category on Parental Support in Public Secondary Schools in Nyahururu and

Laikipia West Districts, Kenya. AFRREV IJAH: An International Journal of Arts and Humanities, 2(2), 169-187.

Kombo, D.K. and Tromp D.L.A (2006). Proposal and Thesis Writing: An Introduction. Nairobi: Paulines Publications Africa

Maina, J.N. (2012). Management strategies utilized by head teachers to promote Child-friendly public primary schools in Embakasi district Nairobi, Kenya University of Nairobi, Kenya,

Ministry of Education, (2010). Policy for Alternative Provision of Basic Education and Training

Nairobi. Government Printers

Ministry of Education. (2014). Inclusive Education: The Way of the Future. Nairobi: Government Printers.

Ministry of Education, Science and Technology. (2013). Monitoring and evaluation report on the Implementation of the child-friendly schools' program in primary schools in

Kenya. State Department of Education.

Mugenda, O.M and Mugenda, A.G (1999). Research Methods: Quantitative and Qualitative 
Approaches. Nairobi : Act Press

Mugenda, A. \& Mugenda,O.(2003)Research Methods: Qualitative Approaches. Nairobi, African Centre for Technology Studies.

Republic of Kenya. (2001). Children's Act, Government Printer, Nairobi

UNESCO. (2001). Review of the present situation in special education. Web accessed:

http://www.unesco.org

. (2001) Understanding and Responding to Children's Needs in Inclusive

Classroom. A guide for Teachers :Paris. . (2010). Education For All. The Quality Imperative Global Monitoring

Report. Paris.

UNICEF (2009). Child Friendly Schools Manual. UNICEF Division of Communication, New

York www.unicef.org http://www.unicef.org/crc/

(2009). Child Friendly Schools Programming Global Evaluation Report. Evaluation Office, Division of Communication, New York www.unicef.org . (2011). UNICEF's Child-Friendly Schools Kenya Case Study. Management Project Office of CFS , NCET New York www.unicef.org http://www.unicef.org/crc/ . (2012) Child-Friendly Schools. www.unicef.org/kenya/media_10400.html http://www.unicef.org/ Retrieved on 4/12/2015.

. (2018). Drinking Water, Sanitation and Hygiene in Schools: Global Baseline Report 2018. WHO/UNICEF Joint Monitoring Programme for Water Supply, Sanitation and Hygiene. UNICEF.

Uwezo. (2013). Kenya National Learning Assessment report 2010. Uwezo: Nairobi.

Wasef, N. H. (2011). Corporal punishment in schools. Thesis Submitted to the Public Policy and

Administration Department in partial fulfillment of the requirements for the degree of Master of Public Policy and Administration. The American University in Cairo School of Global Affairs and Public Policy.

WHO (2014). Sign up to support clean schools. Education, 95(11), 4. 